\title{
Nanotheranostics
}

2017; 1(1): 23-37. doi: 10.7150/ntno.17753

Research Paper

\section{Effects of Cd-based Quantum Dot Exposure on the Reproduction and Offspring of Kunming Mice over Multiple Generations}

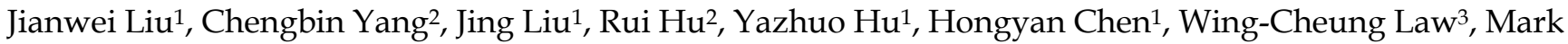 \\ T. Swihart ${ }^{\natural}$, Ling Ye ${ }^{\bowtie}$, Kuan Wang ${ }^{5,6^{\boxplus}}$, and Ken-Tye Yong ${ }^{\circledR}$ \\ 1. Institute of Gerontology and Geriatrics, Chinese PLA General Hospital, Beijing Key Lab of Aging and Geriatrics, Beijing 100853, P.R. China \\ 2. School of Electrical and Electronic Engineering, Nanyang Technological University, Singapore 639798, Singapore \\ 3. Department of Industrial and Systems Engineering, The Hong Kong Polytechnic University, Hung Hom, Kowloon, Hong Kong, P.R. China \\ 4. Department of Chemical and Biological Engineering, University at Buffalo, Buffalo, New York 14260-4200, USA \\ 5. Nanomedicine Program and Institute of Biological Chemistry, Academia Sinica, Nankang, Taipei 115, Taiwan \\ 6. College of Biomedical Engineering, Taipei Medical University, Taipei 110, Taiwan
}

$\triangle$ Corresponding authors: Mark T. Swihart, Department of Chemical and Biological Engineering, University at Buffalo (SUNY), Buffalo, NY 14260-4200, USA, email: swihart@buffalo.edu; Ling Ye, Institute of Gerontology and Geriatrics, Laboratory Animal Center, Chinese PLA General Hospital, Beijing 100853, PR China, email: lye301@aliyun.com; Ken-Tye Yong, PhD, School of Electrical and Electronic Engineering, Nanyang Technological University, Singapore 639798, Singapore Tel: +65-6790-5444, email: ktyong@ntu.edu.sg; Kuan Wang, PhD, Nanomedicine Program and Institute of Biological Chemistry, Academia Sinica, Nankang, Taipei 115, Taiwan, email: wangk007@gmail.com

(C) Ivyspring International Publisher. This is an open access article distributed under the terms of the Creative Commons Attribution (CC BY-NC) license (https://creativecommons.org/licenses/by-nc/4.0/). See http://ivyspring.com/terms for full terms and conditions.

Received: 2016.09.24; Accepted: 2016.11.22; Published: 2017.01.01

\begin{abstract}
The potential health risks associated with heavy-metal containing quantum dots (QDs) are a major concern accompanying their increased application in both research and industry. In this contribution, we investigate the effects of QDs on reproductive outcomes in Kunming mice across three generations. Rather than being exposed to QDs during pregnancy, mice were intravenously injected with phospholipid micelle encapsulated CdSe/CdS/ZnS QDs at a dosage of $0.81 \mathrm{mg} \mathrm{Cd} / \mathrm{kg}$ two weeks before mating. Four treatment groups were studied: non-injected control, female injected, male injected and both parents injected with QDs. Although QDs accumulated in the major organs of treated mice, we did not detect any pregnancy complications or adverse effects. No significant difference in pregnancy outcomes could be identified between the QD treated groups and the control group. More importantly, through behavior monitoring, blood tests and histological evaluations, two generations of the offspring were observed to be in normal and healthy condition. Our results show that QD exposure with a short buffering period before conception does not cause obvious pregnancy complications or significant toxicity effects in treated mice or their offspring. This indicates that a short buffering period after QD exposure may reduce potential risk of QDs to reproductive health.
\end{abstract}

Key words: Quantum Dots; Toxicity; Reproductive Health; Offspring

\section{Introduction}

Cadmium-based quantum dots (QDs) have been extensively studied for applications in biomedical research.[1-4] With their exceptionally bright and tunable photoluminescence, they have shown outstanding performance as optical probes for in vitro and in vivo targeted imaging and sensing.[5, 6]
However, the cadmium content of these QDs has raised serious safety concerns about their translation to clinical settings. Recent in vitro studies have reported the degradation of QDs when they are exposed to biological fluids, releasing toxic $\mathrm{Cd}^{3+}$ ions.[7] Generation of free radicals by QDs has also 
been identified as a mechanism of QD cytotoxicity.[8] However, in vivo studies have generally not shown such effects. Systemic QD toxicity has seldom been detected in vivo, even when they were injected with QD formulations at high dosage $(6 \mathrm{nmol}$ for mice and 12 nmol for rats).[9, 10] More recently, our group has shown that even non-human primates injected with phospholipid micelle-encapsulated CdSe/CdS/ZnS QDs do not exhibit evidence of toxicity over a period of more than one year of evaluation.[11] However, we must not ignore the fact that more than $90 \%$ of the injected cadmium remained in the non-human primates 90 days after exposure, primarily in the kidney, spleen and liver. This suggests that the potential long-term toxicity of QDs in vivo must be carefully investigated. Such studies will help the QD research community to design more robust cadmium-based QDs for specific biological or even clinical research applications. The creation of new types of cadmium-free QDs is also an important and valuable approach. However, many of these QDs formulations are still under development, and they have generally not been able to match the performance of Cd-based QDs. Substantial time will be required to perfect cadmium-free QD formulations to a point where they can match the performance of Cd-based QDs in applications such as in vivo imaging and image-guided surgery.

Recent studies have shown that inorganic nanoparticles (e.g. titania, silica, fullerenes, and QDs) can cause reduced fertility and reproductive system injury in mice. Those studies focused mainly on examining the effects of direct exposure of the fetus and pregnant mothers to nanomaterials. For example, Chu et al. reported the transmigration of QDs from the pregnant mice to their fetuses by a transplacental transport mechanism.[12] The authors found that smaller QDs had greater ability to cross the placenta and thereby induce in vivo toxicity. Yang et al. demonstrated that gold nanoparticles migrated across the placenta of mice and interacted with the fetus, but no adverse response was observed.[13] Wick et al. reported that polystyrene particles up to $240 \mathrm{~nm}$ were able to cross an ex vivo human placental perfusion model without affecting the biological activities of the system.[14] In a more recent study, Yamashita et al. introduced silica and titanium oxide nanoparticles to pregnant mice late in gestation.[15] The results suggested that both silica and titanium dioxide nanoparticles with sizes of $70 \mathrm{~nm}$ and $35 \mathrm{~nm}$, respectively, were able to cause pregnancy complications in mice and adversely impact the growth of the fetus. The authors also indicated that the surface chemistry of the nanoparticles played a major role in determining their effect upon the development of the fetus.[15] Effects on the male reproductive system have also been detected. Yoshida et al. found that intratracheal exposure to $14 \mathrm{~nm}$ and $56 \mathrm{~nm}$ diameter carbon nanoparticles caused adverse effects on the mouse male reproductive function. They observed partial vacuolization of the seminiferous tubules and a decrease of daily sperm production in carbon nanoparticle treated mice.[16] Later, the same group found that fetal nanoparticle exposure of carbon nanoparticles also affected the reproductive function of male offspring.[17] Bai et al. repeatedly injected carbon nanotube dispersions into male mice and found that the testes were injured but the fertility of the mice was not affected.[18] Li et al. have examined the effects of inhaled nanoparticle-rich diesel exhaust on regulation of testicular function in adult male rats. Their results suggested that the nanoparticle-rich diesel exhaust inhalation disrupts the endocrine activity of the male reproductive system.[19] Almost all studies to date have primarily focused on the toxicity to the fetus of direct parental nanoparticle exposure, while few investigations considered the impact of nanoparticles on the offspring of exposed rodent such as mice and rats.[20] Specifically, the effects of nanoparticles on the decendants of treated common parents over multiple generations have not been studied.

Here, we studied two generations of offspring from common parents treated with a QD formulation. The phospholipid micelle-encapsulated CdSe/CdS/ ZnS core/shell/shell structured QD formulation was intravenously administered to the female mice, male mice, or both, two weeks before allowing them to mate. The impacts of QDs on the pregnancy and the litters were evaluated. We have monitored and investigated the fertility and reproductive health of the offspring of the common parents in each group for two generations. Our results show that with a buffering period of two weeks between the QD injection and conception, the nanoparticles do not cause any significant pregnancy complications or abnormal pregnancy outcomes. Although the majority of the QDs injected accumulated in the major organs of the treated animals, no adverse response was observed for the treated parents or their offspring. Through behavior monitoring, blood testing, and pathological examination, we could not differentiate the QD treated animals from the control group. More importantly, we have continuously monitored the litters for two generations and found that the behavior and blood test results remained indistinguishable between the litters from QD treated groups and the control group. Histological 
investigations on the major organs as well as the sex organs of these two generations did not show abnormalities. These results indicate that with a buffering period before conception, exposure to engineered QDs may not cause significant pregnancy complications or adverse impact on the exposed animals or their offspring.

\section{Materials and Methods}

QD formulation preparation: $1.6 \mathrm{mmol} \mathrm{CdO}, 3$ $\mathrm{mmol}$ TDPA, and $3 \mathrm{~g}$ TOPO were heated in a $100 \mathrm{ml}$ three-necked flask to $290-300{ }^{\circ} \mathrm{C}$ under argon. After 10 to 15 minutes, a clear solution was obtained. It was maintained at $300^{\circ} \mathrm{C}$ for 5 minutes, then $0.8 \mathrm{~mL}$ of $1 \mathrm{M}$ TOP-Se was rapidly injected. The reaction was stopped after 2-3 minutes by removing the heating mantle. QDs were collected by addition of ethanol and centrifugation. The CdS/ZnS graded shell was formed following the method of Manna et al.[21] Approximately $0.3 \mathrm{~g}$ CdSe QDs were dispersed in 4.8 $\mathrm{mL}$ toluene. Separately, $1 \mathrm{mmol} \mathrm{CdO}, 4 \mathrm{mmol}$ zinc acetate, and $7 \mathrm{~g}$ TOPO were dissolved in $10 \mathrm{~mL}$ oleic acid and heated to $180^{\circ} \mathrm{C}$ for 28 minutes under argon. The QD dispersion was injected slowly into the hot mixture, which was then held at $180^{\circ} \mathrm{C}$, with a needle outlet that released evaporating toluene. After 15 minutes, the needle was removed, and the temperature was raised to $210^{\circ} \mathrm{C} .2 \mathrm{~mL}$ of TOP-S was then added dropwise, and the mixture was held at 210 ${ }^{\circ} \mathrm{C}$ for 10 to 15 minutes. To monitor the growth of the QDs, aliquots were removed via syringe and injected into excess toluene to quench further growth of the QDs and the fluorescence were measured. The growth of QDs were stopped when the photoluminescence peak reached $620 \mathrm{~nm}$.

Phopholipid-micelle encapsulation: The prepared organic-dispersible QDs were collected by adding ethanol (volume ratio of QDs to ethanol 1:3) and centrifugation at 12,000 rpm for 15 minutes. The precipitate was collected and dried under vacuum and then re-dispersed in chloroform at the final concentration of $4 \mathrm{mg} / \mathrm{ml}$. Chloroform dispersions of QDs, and of DSPE-mPEG (Avanti polar lipids or Laysan Bio, Inc., 1,2-Diacyl-sn-Glycero-3-Phosphoethanolamine-N-[Methoxy(Polyethylene glycol)], 10 $\mathrm{mg} / \mathrm{mL}$ ) were mixed in a 1:4 mass ratio and gently stirred for 5 to 10 minutes. A Labconco rotory evaporator with a water bath of $25{ }^{\circ} \mathrm{C}$ was used to evaporate the chloroform. The resulting lipidic film was hydrated with 3 to $5 \mathrm{~mL}$ of HPLC water and sonicated for 10 to 15 minutes using a bath sonicator. The resulting dispersion was filtered through a 0.45 or $0.2 \mu \mathrm{m}$ membrane filter and kept at room temperature for further use. To remove excess phospholipid, the micelle-encapsulated QDs were centrifuged at 10,000 rpm for 15 minutes. The precipitate was then re-dispersed in 1 to $2 \mathrm{~mL}$ of HPLC water. For QD injection, $10 \mathrm{mg} / \mathrm{mL}$ QDs was dispersed in $0.9 \%$ sodium chloride and filter sterilized.

Characterization: The absorption spectra of QDs were collected using a Shimadzu UV-2450 UV-Vis-NIR scanning spectrophotometer. The samples were measured against the solvent as reference. The QD fluorescent spectra were collected using a Fluorolog-3 Spectrofluorometer (HORIBA Jobin Yvon, Edison, NJ USA). The samples were dispersed in chloroform and loaded into a quartz cuvette for measurements. Transmission electron microscopy (TEM) images were obtained using a JEOL model JEM 2010 microscope. The specimens were prepared by drop-casting the sample dispersion onto an amorphous carbon coated 300 mesh copper grid, which was placed on filter paper to absorb excess solvent. The size distribution of micelle-encapsulated QDs was determined by dynamic light scattering (DLS) measurements with a Brookhaven Instruments 90Plus particle size analyzer.

Animal studies: Kunming mice were obtained and handled following protocols approved by the Laboratory Animals Center of Chinese PLA General Hospital in Beijing. All the animal experiments and maintenance were approved by the Experimental Animal Ethics Committee of Chinese PLA General Hospital. Male and female Kunming mice were obtained at 10 weeks of age and were housed 2 per cage in a $12 \mathrm{~h} / 12 \mathrm{~h}$ light/dark cycle. Food and water were supplied ad libitum. Mice were injected with 150 $\mu \mathrm{L}$ of vehicle control or buffered QD dispersion. Two weeks after the injection of $0.81 \mathrm{mg}(7.2 \mu \mathrm{mol}) / \mathrm{kg}$ of cadmium decided based on our previous report[22], mice were randomly grouped into four different groups as described in the text. In each group, male and female mice were paired on a one-to-one basis and housed to mate. The show of plug was used as a marker of conception, and the day was regarded as GD0.

H\&E staining and Fluorescent imaging: pathological analysis of mouse tissue, mice were sacrificed by cervical dislocation. Heart, liver, spleen, lungs, kidneys, lymph nodes, bone marrow, uterus, and ovaries were collected, dissected and fixed with $10 \%$ buffered formalin. Then were subjected to paraffin embedding. These embedded tissues were sectioned, deparaffined, rehydrated and subjected to Hematoxylin and Eosin (H\&E) stained. H\&E sections of the fixed organs were observed with an Olympus BX60 microscope, and were examined by two independent clinical pathologists who were not told 
what treatment mice had undergone or which samples were from the control mice. Standard cryosection procedures were performed for fluorescent imaging of the organs of interests. The fluorescent images were taken from a typical inverted microscope based fluorescent imaging system.

Analysis of hematological and serum biochemical marker: According to our previous experience[23], blood samples are harvested from F0 mice injected with CdSe/CdS/ZnS QDs and F1 mice after mice were sacrificed by cervical dislocation. Blood is harvested from the orbital sinus by removing the eyeball from the socket quickly. Blood routine examination is performed using the whole blood by a routine blood test instrument (Mindray RJ-0C107223), and indicators for kidney and liver function are measured using serum by a blood biochemistry analyzer (Mindray BS-220).

Statistical analysis: Statistical analysis was performed using analysis of variance (ANOVA). All statistical calculations were performed with the SPSS 11.0 software package. Student's unpaired two-tailed t-test was used for binary comparisons. A $P$ value less than 0.05 was regarded as statistically significant. Data are presented as mean \pm SD .

\section{Results and Discussion}

Micelle-encapsulated CdSe/CdS/ZnS core/ shell/shell QDs were prepared following our previously described protocols.[22] Figure 1 shows results of optical and physical characterization of the QD dispersion. The QDs have an emission peak at 620 $\mathrm{nm}$ with a full with at half maximum of $43 \mathrm{~nm}$. The average hydrodynamic diameter of the micelle-encapsulated QDs was $62.4 \pm 0.8 \mathrm{~nm}$. TEM imaging showed that multiple QDs were encapsulated within a micelle to form relatively large QD-containing particles, consistent with the measured hydrodynamic diameter. A schematic illustration of our experimental design is shown in Figure 2. Female () and/or male ( $\left.\jmath^{1}\right)$ mice were treated with QDs $(+)$ at cadmium content of $0.81 \mathrm{mg}$ $(7.2 \mu \mathrm{mol}) \mathrm{Cd} / \mathrm{kg}$ body weight. Control animals were injected with saline buffer $(-)$. Specifically, four different experimental groups were designed (ten female and ten male mice in each experimental group), namely, i) control group $+\phi_{-} / \hat{o}-$, in which neither female nor male mice were treated with QDs; ii) group $+-/ \hat{\jmath}^{+}$, in which only the male mice were treated with QDs; iii) group $++/ \hat{o}-$, in which only the female mice were treated with QDs; and iv) group $\mathrm{C}^{+} / \mathrm{o}^{+}$, in which both female and male mice were injected with QDs. In this study, a monogamous breeding system was used and the selected pairs were allowed to breed two weeks after QD exposure. The QD-treated generation is referred to as F0. Then, the litters obtained from the F0 generation of common parents were grown to sexual maturity at seven weeks of age and subsequently this first generation of males and females were paired to produce the second generation following a similar monogamous breeding system. The litters generated from the first and second generations are referred to as F1 and F2, respectively.
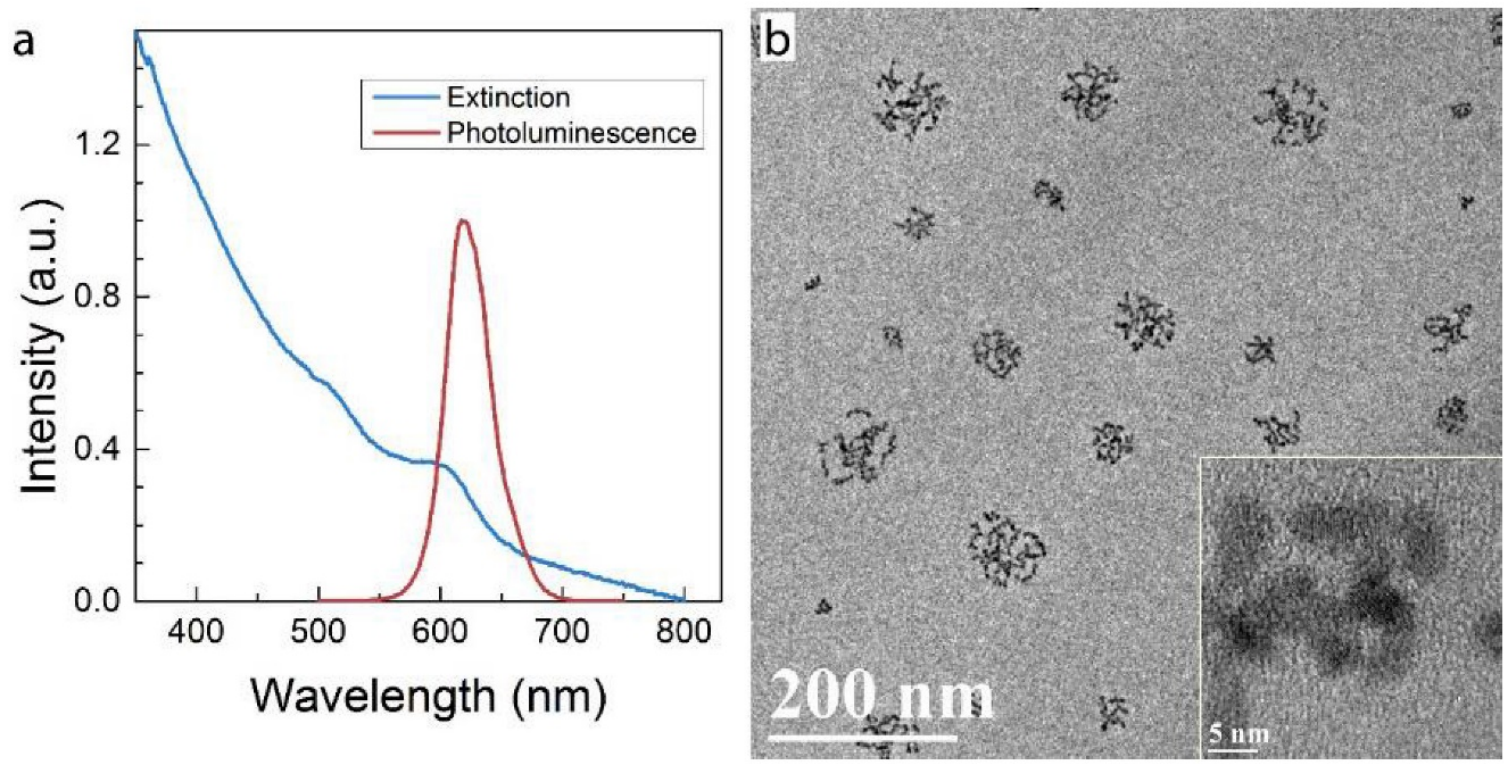

Figure 1. Characterization of QD formulation. a) Extinction and photoluminescence spectra of QDs, showing a PL emission peak at $620 \mathrm{~nm}$ with a full width at half maximum of $43 \mathrm{~nm}$ b) TEM images of QDs after phospholipid encapsulation. The inset shows a high resolution TEM image in which crystal lattice fringes of the QDs are visible. Note that in this formulation, multiple QDs are encapsulated in each micelle. 

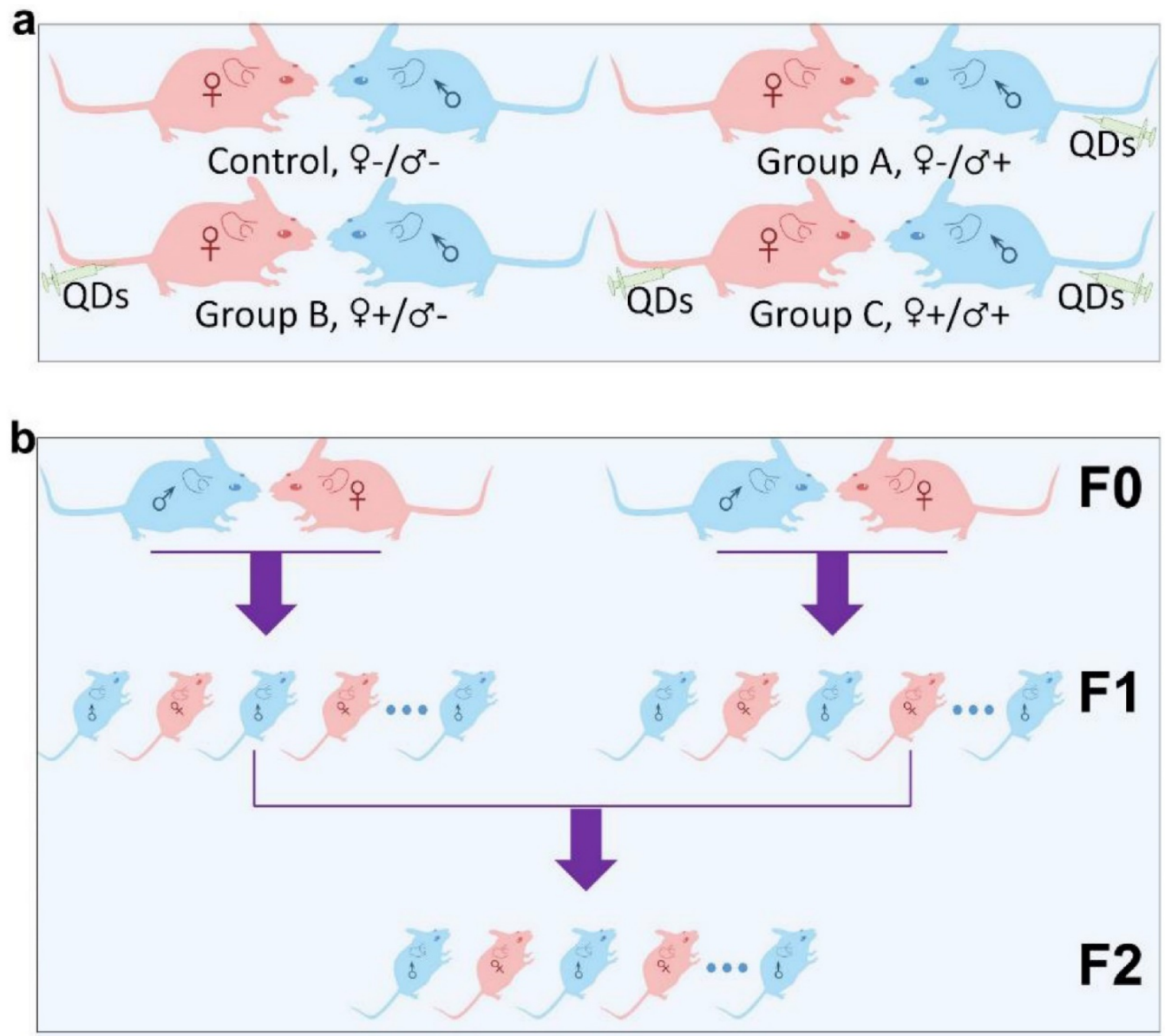

Figure 2. Schematic illustration of the experimental design. (a) The QD treated (+) or non-treated (-) female ( $\$)$ and male ( $\odot)$ mice were divided into four different groups, namely Control \&-/ $/$-, Group A \&-/ $/$ +, Group B $\&+/ \odot-$ and Group C $\&+/ \odot^{+}$. (b) Within each group, mice from the F0 generation were randomly matched on a "one-to-one" basis to produce a first offspring generation, denoted the F1 generation. An F2 generation was obtained by randomly pairing members of the Fl generation, within each group, after they had reached sexual maturity.

The intravenous administration of QDs to the F0 group did not cause any observable adverse response in either the male or female mice. No changes were observed in drinking or eating patterns compared to the mice treated with saline solution. The consumption of the laboratory chow and drinking water was monitored on a daily basis, and no differences were observed between the QD-treated and the control animals. Responses to various stimuli were found to be similar between the mice in all groups. We did not observe any signs of toxicosis, such as vomiting, diarrhea, convulsion, cramps, or breathing difficulties, following QD treatments. After breeding of the F0 group, the health of the pregnant females and their newborn litters were carefully monitored. The maternal body weight changes of mice in all four groups were monitored as a function of gestational age. As shown in Figure 3a, all treated groups showed a steady increase in maternal body weight that was nearly identical to that of the control group. In addition, the gestational duration of the F0 group and the total number of offspring were recorded for all cases, as shown in Figure $3 \mathrm{~b}$. The gestational ages at birth ranged from 18 to 21 days. Differences in average gestational age at birth across the treatment groups were not statistically significant. The total numbers of pups per litter ranged from 9 to 18 for all F0 females and the average numbers were $14.0,13.9,13.5$ and 12.6 for the $+-/ \delta-,+9-/ \delta+, q+/ \hat{o}-$ and $++/ \delta+$ groups, respectively. The differences between the groups were not statistically significant. After delivering the newborns, the body weight of the female mice was monitored for another two weeks. As shown in Figure 3c, body weight increased gradually for mice in all four groups and this increase was equivalent in all four groups. 

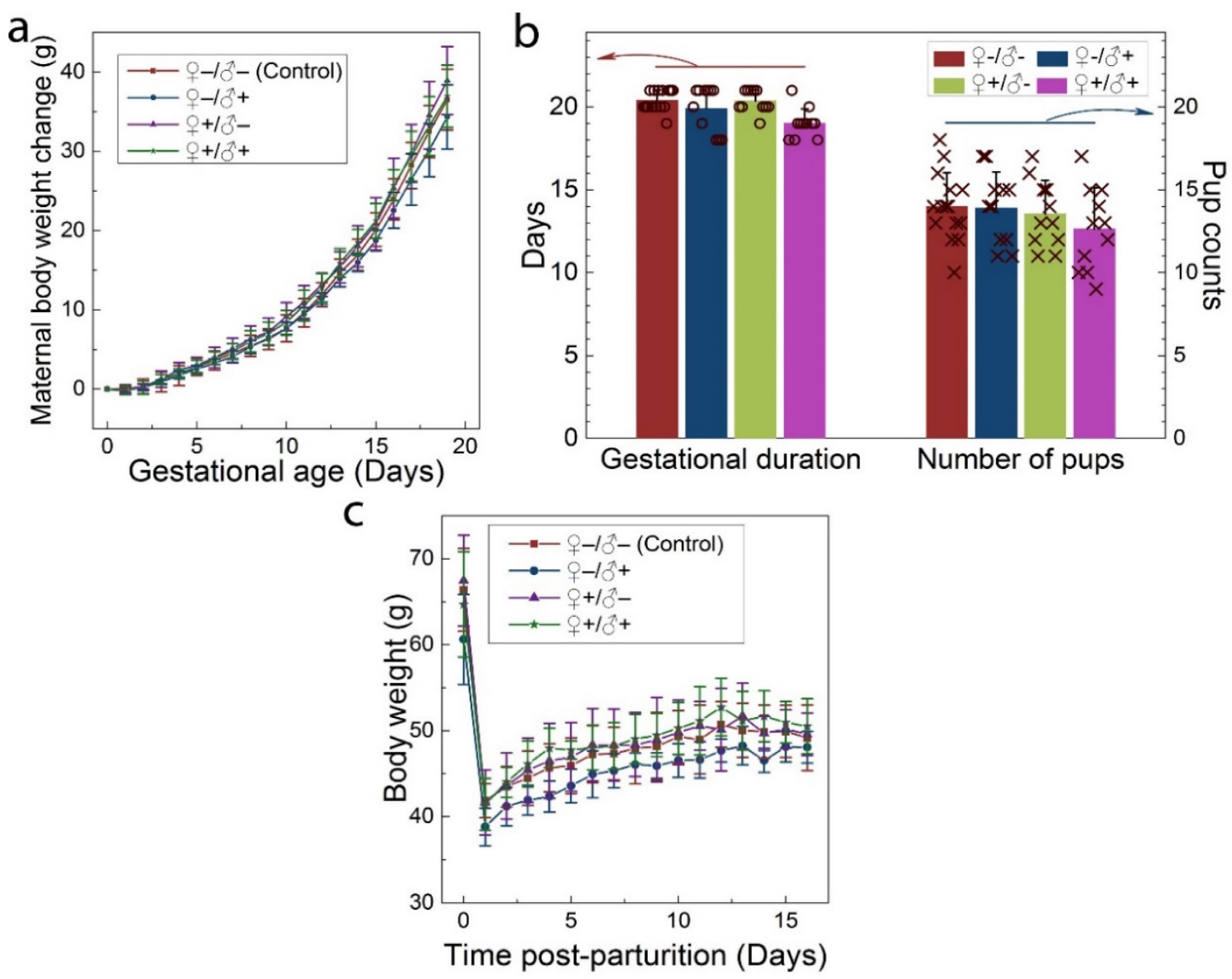

Figure 3. Maternal statistics of the F0 generation during the pregnancy and lactation period. a) Maternal body weight change during the gestation period for animals in the four experimental groups. b) The average gestational duration $(20.4 \pm 0.63,19.9 \pm 1.38,20.4 \pm 0.67$ and $19.0 \pm 0.89$ days for the $\$-/ \varnothing-$, $\$-/ \odot+$, $\&+/ \varnothing-$ and

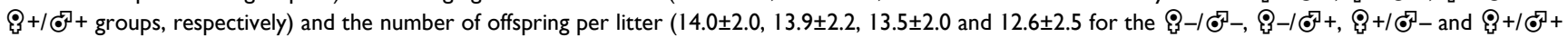
groups, respectively). In each group, scattered points show results for individual mice in each group. No statistically significant differences (defined as $P<0.05$ for pairwise comparison between groups) were observed. c) The average maternal body weight recorded during the lactation period for mice in each group. For all figures, error bars indicate $\pm S D, n=10$.

The placenta plays an important role in the development of the fetus. Its functions include nutrient uptake, waste elimination, and gas exchange through the maternal blood supply.[24] In a recent study by Yamashita et al., the authors introduced 70 $\mathrm{nm}$ silica and $35 \mathrm{~nm} \mathrm{TiO}_{2}$ nanoparticle dispersions into pregnant mice and observed that these particles induced placental cellular damage and were found in fetal blood circulation.[15] In another study, Chu et al. showed that CdTe/CdS QDs were transferred from female mice to their fetuses across the placental barrier. Surface PEGylation of the QDs reduced the transfer but did not eliminate it.[12] Bhabra et al. have shown that nanoparticles of $29.5 \pm 6.3 \mathrm{~nm}$ in diameter may cause DNA and chromosome damage across an intact cellular barrier.[25] They found out that even though the nanoparticles did not pass through the barrier, the damage was mediated by a mechanism involving pannexin and connexin hemichannels and gap junctions and purinergic signaling. Such observations underscore the importance of detailed nanomaterials toxicity evaluation. To further evaluate the potential risk of QD exposure, we carefully examined and analyzed the placenta from both the QD-treated and non-treated mice. Eighteen days after delivering the newborns, five QD treated maternal mice were sacrificed and examined. We did not observe any accumulation of QDs in the placenta sections using fluorescence imaging (Fig. 4a shows a typical example). The histological analysis did not reveal any pathological abnormalities in the evaluated placenta sections of the treated pregnant mice (Fig. $4 \mathrm{~b}$ shows a typical example). The labyrinth and spongiotrophoblast features in the mice placenta were clearly observed. These findings suggest that the intravenous administration of QDs into female mice two weeks before conception will not affect the development of the placenta or result in any observable cellular damage to the placenta.

To investigate the possible adverse effects of the QD formulation on female mice after delivering newborn litters, a detailed evaluation on the health 
condition of the mothers was carried out. Standard hematological and biochemical markers were measured for all the F0 female mice. No significant differences were observed on the routine blood count measurements between the QD treated and non-treated female mice (Fig. 5a). This indicates that the QD dispersion did not induce any immune or inflammatory responses after the female mice delivered their litters. From the serum biochemistry assays, we have observed that the important hepatic function and renal function indicators are all comparable with the non-treated controls (Fig. 5b). These data indicate that the QDs did not produce any substantial liver or kidney injury. In addition to serum study, histological analysis was performed on the major organs of the female mice. No pathological abnormalities were identified from the heart, liver, spleen, lung or kidneys of QD treated female mice (Fig. 5c). Fluorescence imaging suggests that the QDs were located mainly in the liver, spleen, lymph node and bone marrow (Fig. 5d). Similar observations have been reported in earlier studies from different animal models. For example, using near infrared imaging, Ballou et al. have observed that PEGylated QDs accumulate mainly in the mouse liver, lymph nodes and spleen $24 \mathrm{~h}$ after injection, while the fluorescence in the lymph nodes was still detectable 133 days post-injection.[26] Our group has also observed that the target organs for PEGylated QDs are the liver, spleen, lymph node and bone marrow, in both mouse and monkey models.[22, 27] We also found that the same dosage of the identical QD formulation did not cause noticeable toxicity to mice or monkeys.[22, 27] It should be noted that the surface modification of nanoparticles plays an important role in their in vivo toxicity. In our studies, the PEGylation of QDs was realized through phospholipid encapsulation. In another study from Tang et al., the QDs were encapsulated by an amphiphilic copolymer rich in carboxylate groups followed by further covalent conjugation of PEG chains. Their PEGylated QD formulation was found to cause injuries in specific tissues, such as hyperplasia and hyperaemia in the splenic sinus, and syncretized podocytes in the kidneys after acute exposure with a relatively high dosage of $10 \mathrm{nmol} / \mathrm{kg}$.[28] These results indicate that even for similar surface status (PEGylation), different modification strategies may cause different outcomes in toxicity evaluation. In vitro studies have shown that nanoparticles could cause damage to cells from the reproductive system, such as the sperm, embryonic stem cells and leydic cells.[20] To address this issue, the major reproductive organs of both the female and male mice including the uterus, ovary and testis were carefully examined. Frozen sections of the organs were examined by fluorescence microscopy, and no QD fluorescent signal was observed in these organs (Fig. 6a). This indicates that the deposition of QDs in these organs is very low. Pathological evaluations of the tissues were also carried out. No pathological changes were observed in these reproductive organs for mice treated with QDs as compared with the mice in the saline treated control group (Fig. 6b). These observations suggest that the PEGylated QD formulation used in this study did not cause noticeable damage to the reproductive organs.
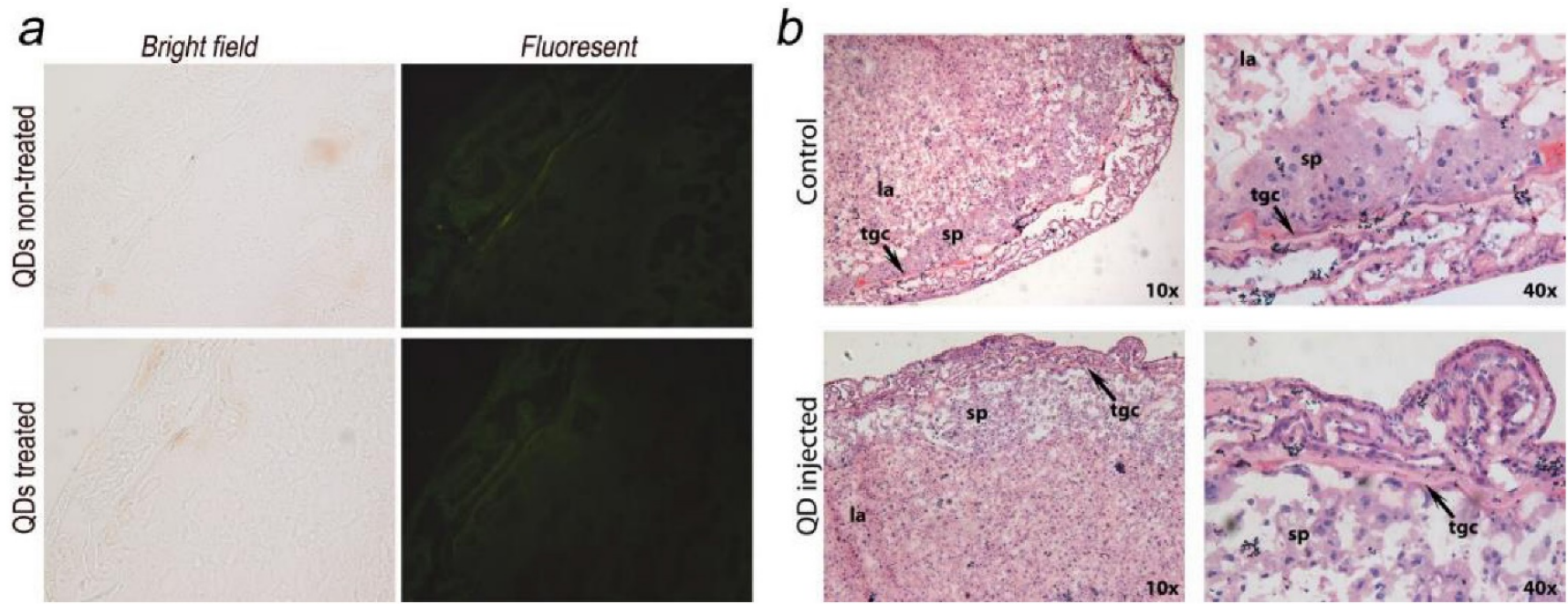

Figure 4. Maternal placenta examination of the FO mice. a) Bright field and fluorescence images of placenta samples from both QD treated and non-treated mice. No fluorescence signals from QDs were observed. b) Histological images of the placenta sections (standard haematoxylin and eosin staining) of the QD treated mice and non-treated mice. Detailed placenta structures are labeled. No differences or abnormalities were observed. sp, spongiotrophoblast; tgc, trophoblast giant cell; la, labyrinth. 

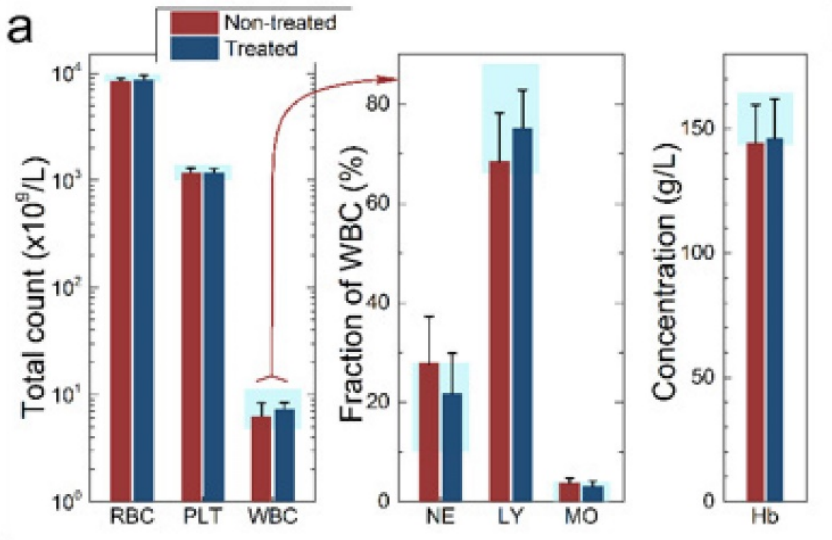

b

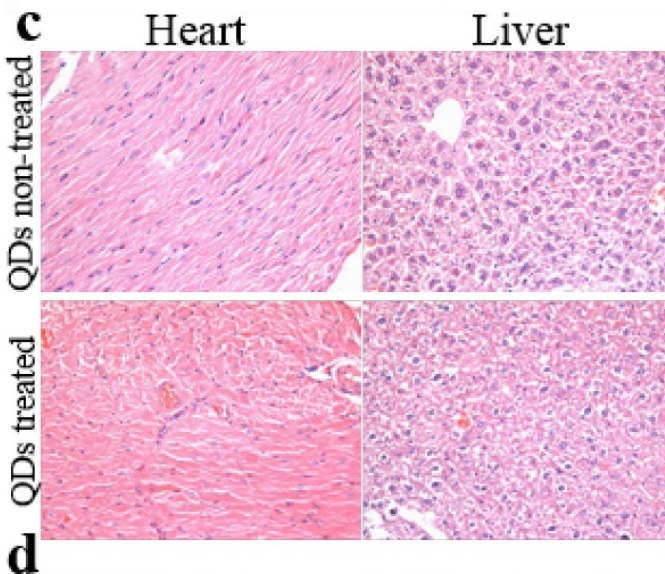

Spleen
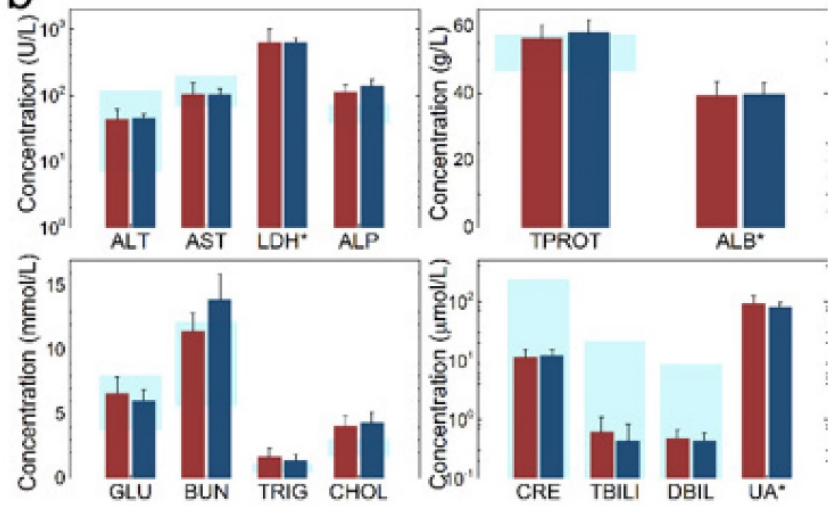

$\frac{c}{\text { c }}$
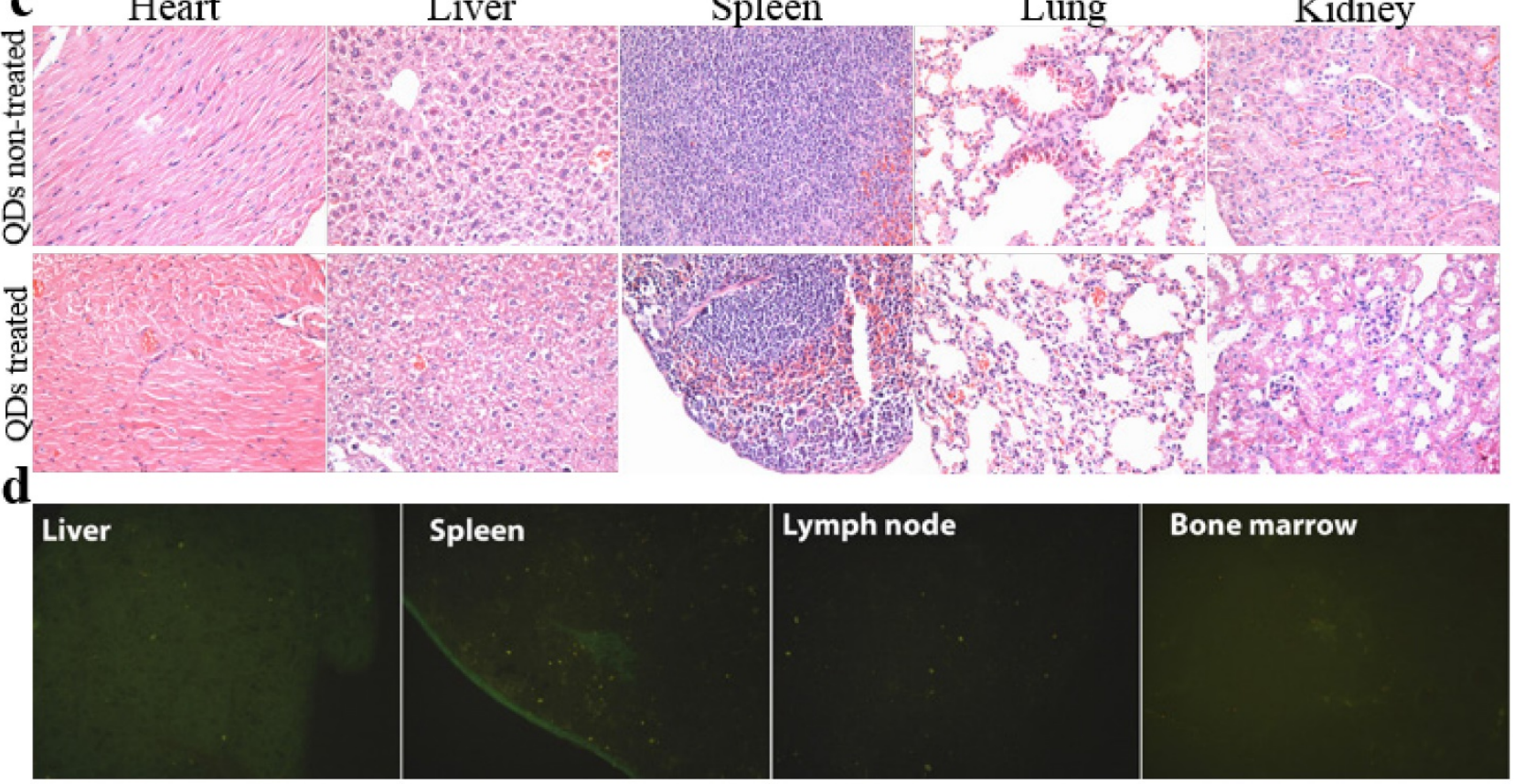

Figure 5. Characterization of the maternal health of F0 mice. Routine blood count (a) and serum biochemistry assays (b) of F0 female mice where the light blue bars denote the averaged normal ranges for mice from the literature. Comparable results were observed between the QD treated and non-treated mice. Note that several values were not in the reference range indicated by the light blue bars which is probably because of different measurement methods. Abbreviations: red blood cell count, RBC; platelet count, PLT; white blood cell count, WBC; neutrophil granulocyte, NE; lymphocyte, LY; monocyte, MO; alanine transaminase, ALT; aspartate transaminase, AST; lactate dehydrogenase, LDH; alkaline phosphatase, ALP; total protein, TPROT; albumin, ALB; blood glucose, GLU; blood urea nitrogen, BUN; triglyceride, TRIG; total cholesterol, CHOL; creatinine, CRE; total bilirubin, TBILI; direct bilirubin, DBIL; uric acid, UA. Bars indicate \pm SD, no statistically significant differences were recorded $(P<0.05)$ between the control and QD-treated groups, $\mathrm{n}=10$. (c) Histological images from the major organs including heart, liver, spleen lung and kidney of the FO female mice, showing no observable differences between the QD treated and non-treated animals. (d) Fluorescence images of major organs showing QD signals, including liver, spleen, lymph node and bone marrow.

The development and health status of the litters produced within two generations from the common parents were evaluated possible adverse impacts on them. The average body weight of the first generation litters was monitored during the lactation period (Fig. 7). No statistically significant difference in the body weight of the litters produced in the first generation was observed between the four groups. In addition, during daily regular observations, we did not observe any differences in water or food consumption between groups. Mice were similarly responsive to various stimuli in each experimental group. Regular blood tests were carried out to check the health status of the first generation mice. The result shows no significant differences in either the hematology analysis or the critical biochemical markers for between the four different experimental groups for both female (Fig. 8a, b) and male mice (Fig. 8c, d). The alanine aminotransferase (ALT) and aspartate aminotransferase (AST) are within the normal range, indicating normal liver function. The creatinine (CRE) levels also indicate healthy kidney function. To further investigate the developments of the litters in the F1 generation, histological analysis on the major 
organs such as the heart, liver, spleen, lung and kidneys were carefully conducted. We did not observe any pathological abnormalities in the F1 mice produced from the four experimental groups (Fig. 9). In addition, we have further investigated the reproductive organs of the mice in the $\mathrm{F} 1$ generation through pathological evaluation. As shown in Fig. 10, the oocytes in the follicle centers are clearly observed and the follicular structures are intact in the ovary sections. The uterus sections are also free of abnormal signs. In the male testis sections, varying stages of sperm formation could be clearly identified. a QDs non-treated
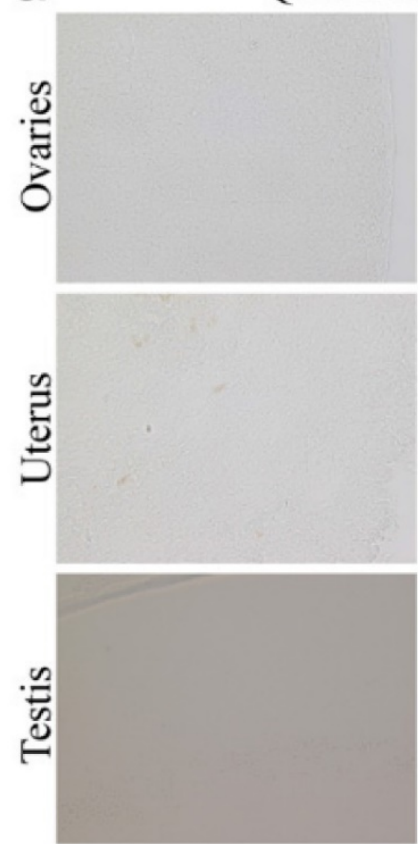

b
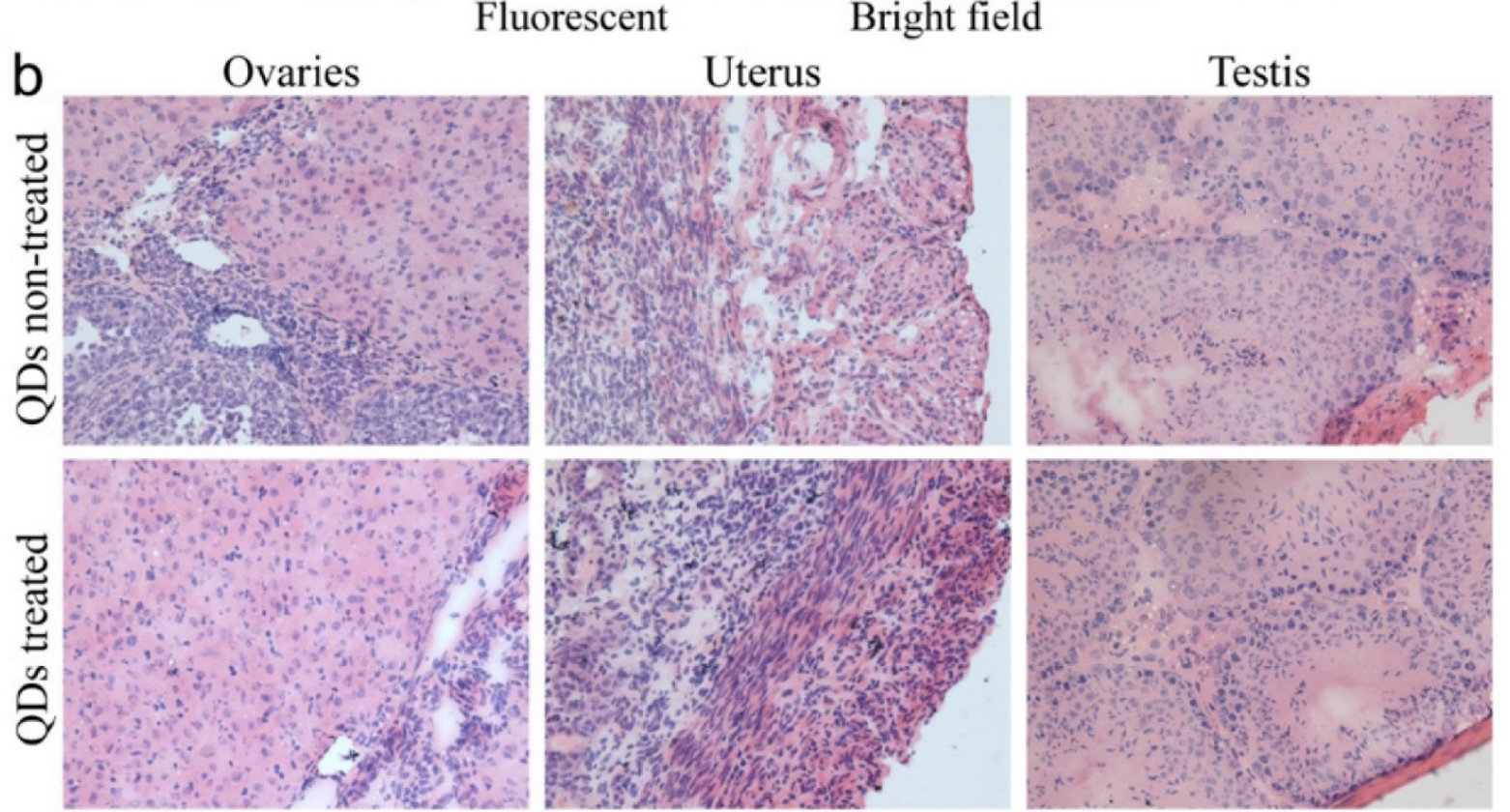
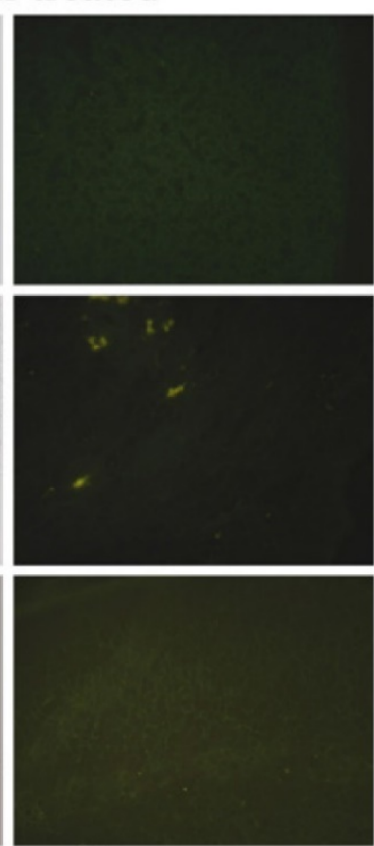

Fluorescent

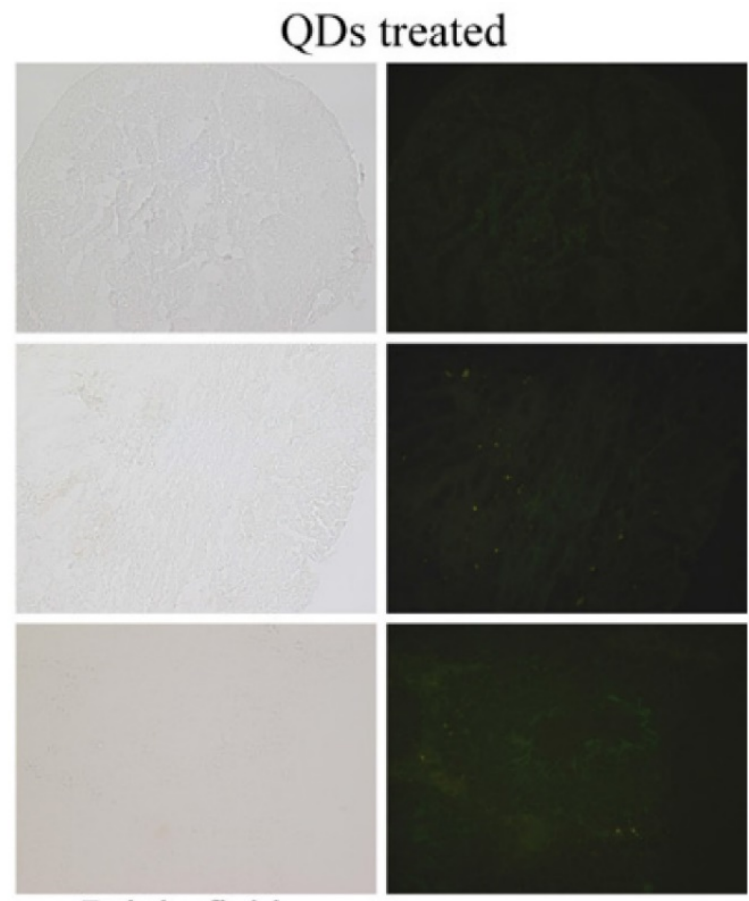

Bright field

Figure 6. Detailed examination of major reproductive organs of the F0 mice, including the ovaries and uterus of the female mice and the testes of the male mice. (a) Fluorescence imaging comparison between the QD treated and non-treated mice. (b) The histological images of the major reproductive organs of the mice. All results are normal, with no indication of pathologies induced by the QDs. 


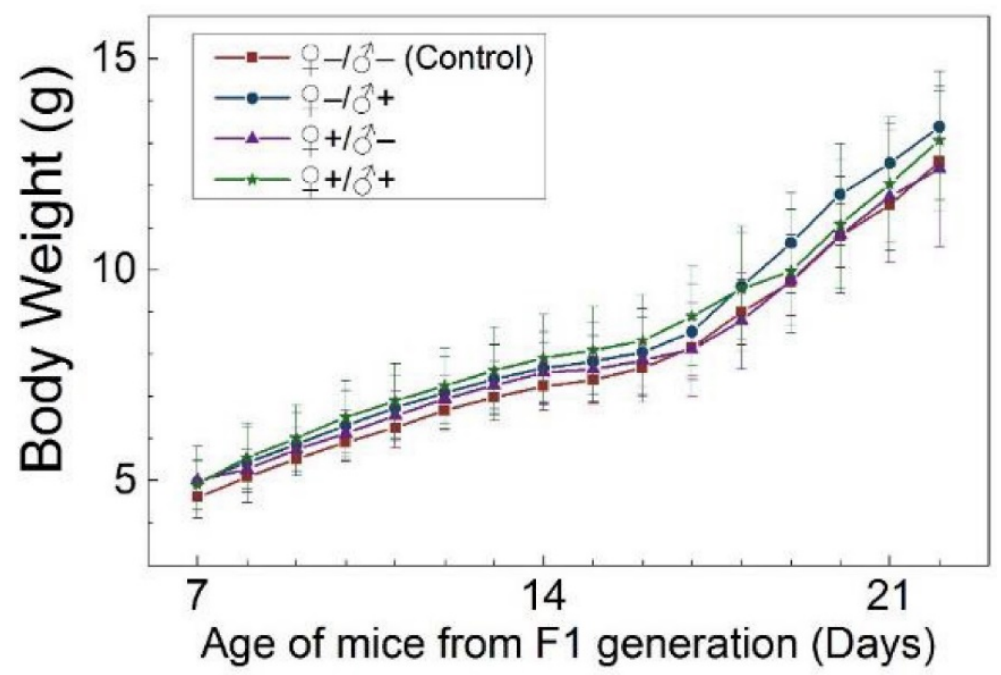

Figure 7. Average body weight of mice of the $\mathrm{F} 1$ generation of the four treatment groups: $\&-/ \odot-($ control), $\&-/ \odot+, ~ \&+/ \odot-$ and $\&+/ \odot+$. Bars indicate \pm SD, $n=10$.

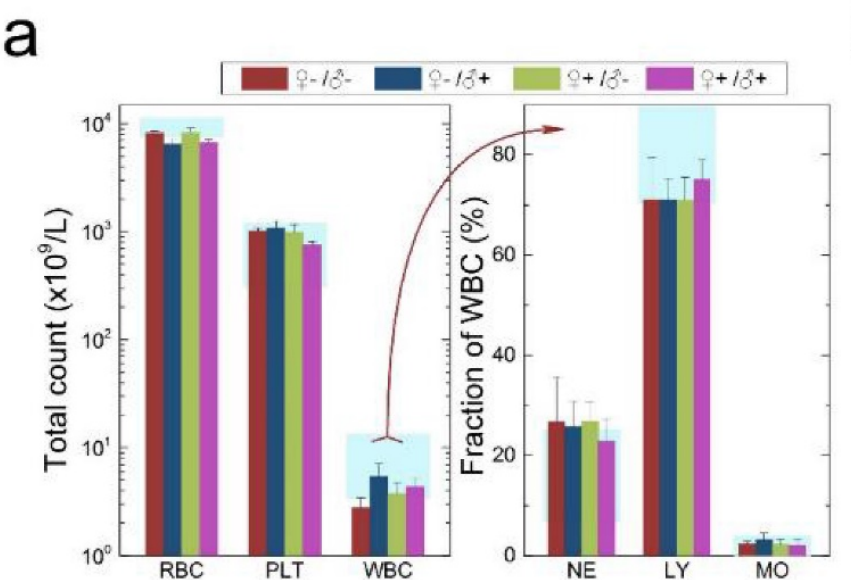

C

b
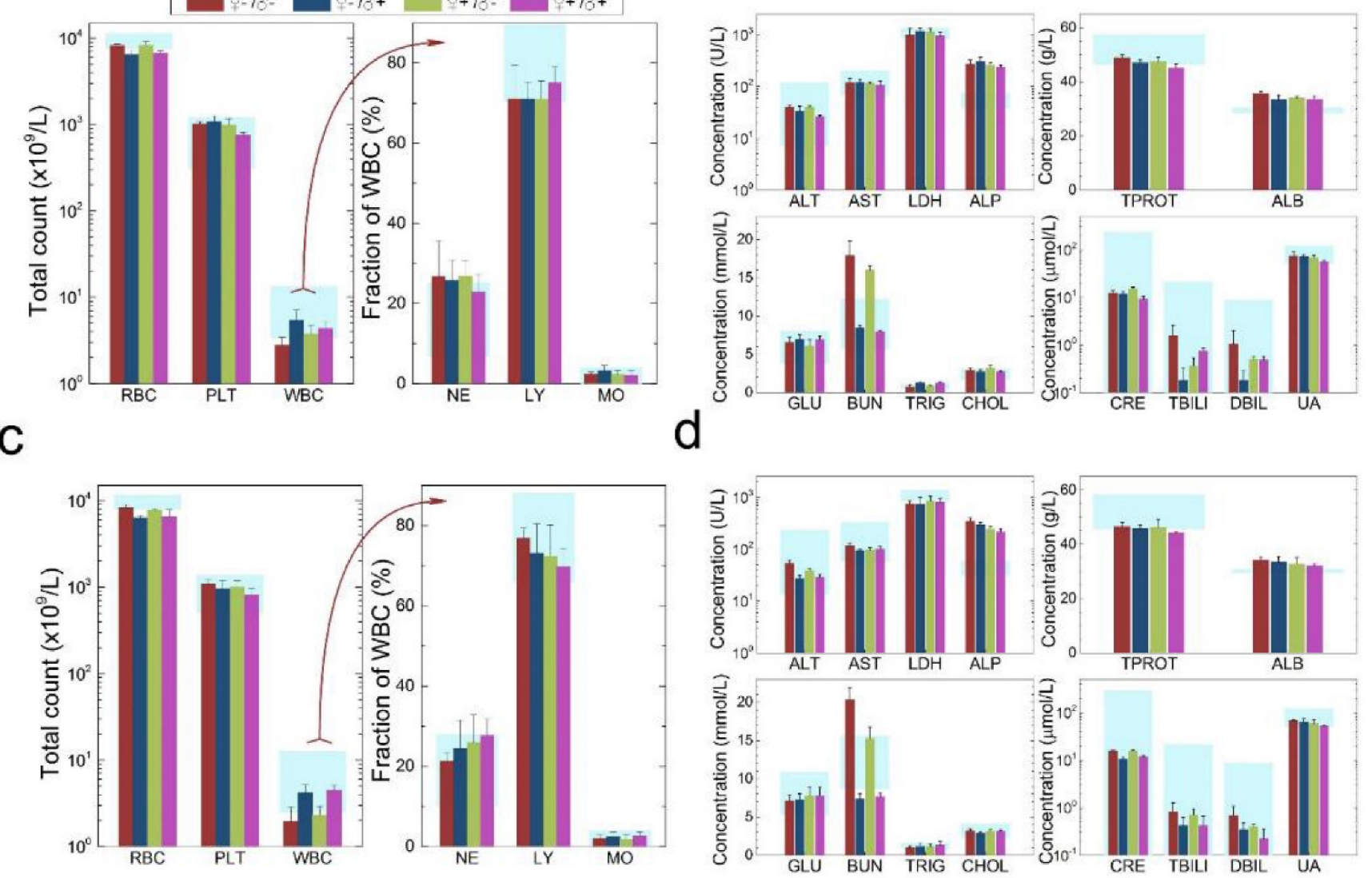

Figure 8. Characterization of the health conditions of F1 mice. Hematology analysis and the critical biochemical markers for F1 female (a, b) and male mice (c, d). Comparable values were observed for the four different experimental groups. Light blue bars denote the averaged normal ranges for mice from the literature, bars indicate $\pm S D, n=18$. Abbreviations: red blood cell count, RBC; platelet count, PLT; white blood cell count, WBC; neutrophil granulocyte, NE; lymphocyte, LY; monocyte, MO; alanine transaminase, ALT; aspartate transaminase, AST; lactate dehydrogenase, LDH; alkaline phosphatase, ALP; total protein, TPROT; albumin, ALB; blood glucose, GLU; blood urea nitrogen, BUN; triglyceride, TRIG; total cholesterol, CHOL; creatinine, CRE; total bilirubin, TBILI; direct bilirubin, DBIL; uric acid, UA. 


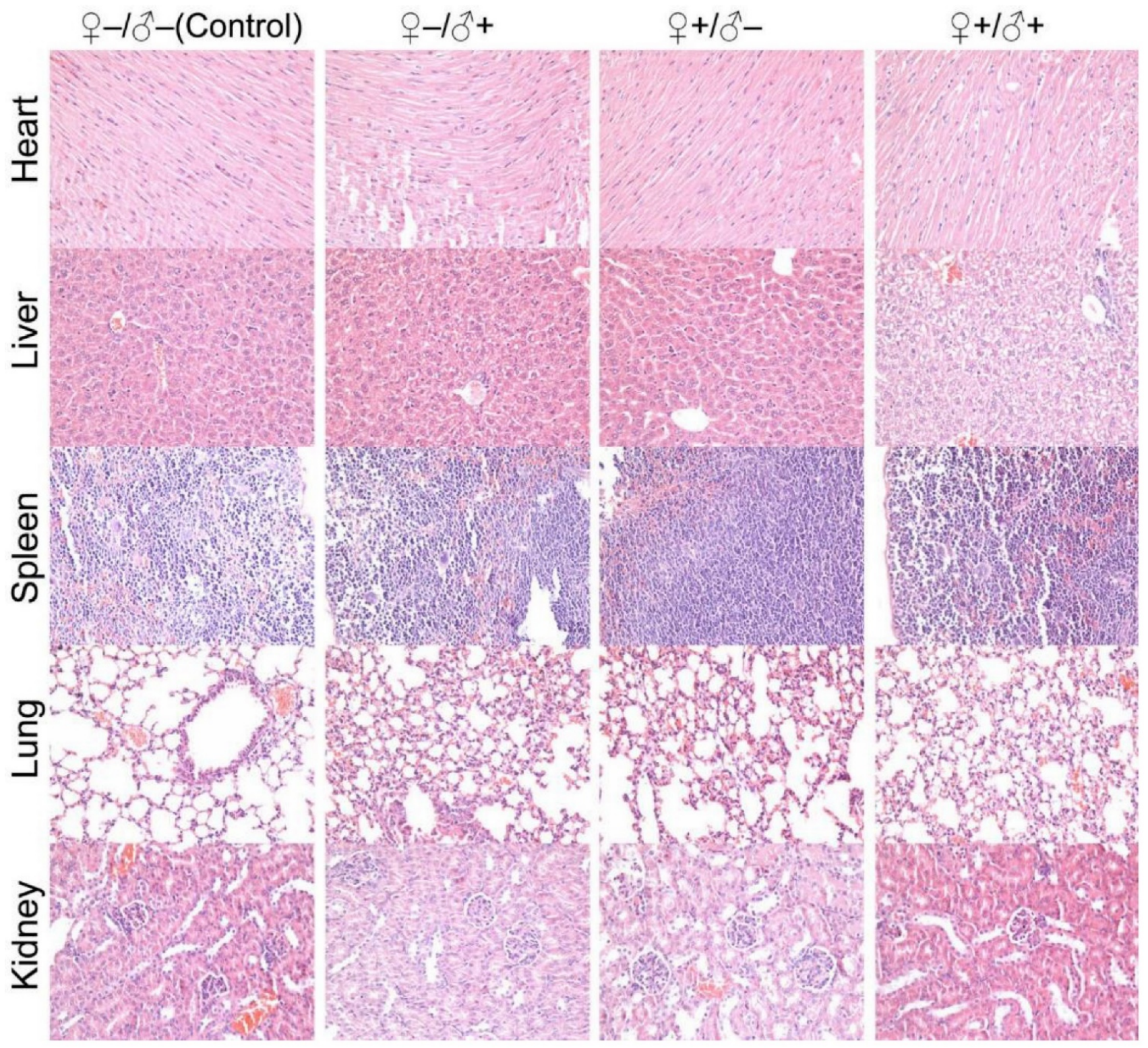

Figure 9. Histological images from the major organs of heart, liver, spleen, lung and kidney for mice from the Fl generation of the different treatment groups of $\&-/ \odot-$ (control), $\&-/ \odot+, \&+/ \odot-$ and $\&+/ \odot+$. Evaluations were carried out by pathologists and no abnormalities were observed.

In our subsequent experiments, the F1 mice from the four experimental groups were paired to produce a second generation of litters using a monogamous breeding system, following the same four sets of experimental conditions as schematically illustrated in Figure 2. Similarly, no abnormal signs were noticed from the first generation female mice that underwent pregnancy with success. The health status of the second generation mice was also evaluated and we found that they were in good condition. We did not observe abnormalities in the exploratory behavior, drinking and eating behaviors (i.e., water and food consumption were normal) or autonomic movements. Responses to various stimuli were also found to be normal. In studies of the second generation, the exponential increase of animal quantity required us to randomly select mice from the entire second generation population for examination. Pathological investigations on the major organ tissue sections obtained from the second generation of male and female mice did not show any abnormalities. Particularly, we have carefully evaluated the histological sections of the sex organs from the F2 generation. Although we have randomly picked the litters, all the organ sections did not show observable pathological abnormalities (Fig. 11). All these results suggest that the mice produced within 2 generations of parents that have been injected with the QD formulation did not show any observable adverse impacts in terms of their reproductive systems or their health status. 

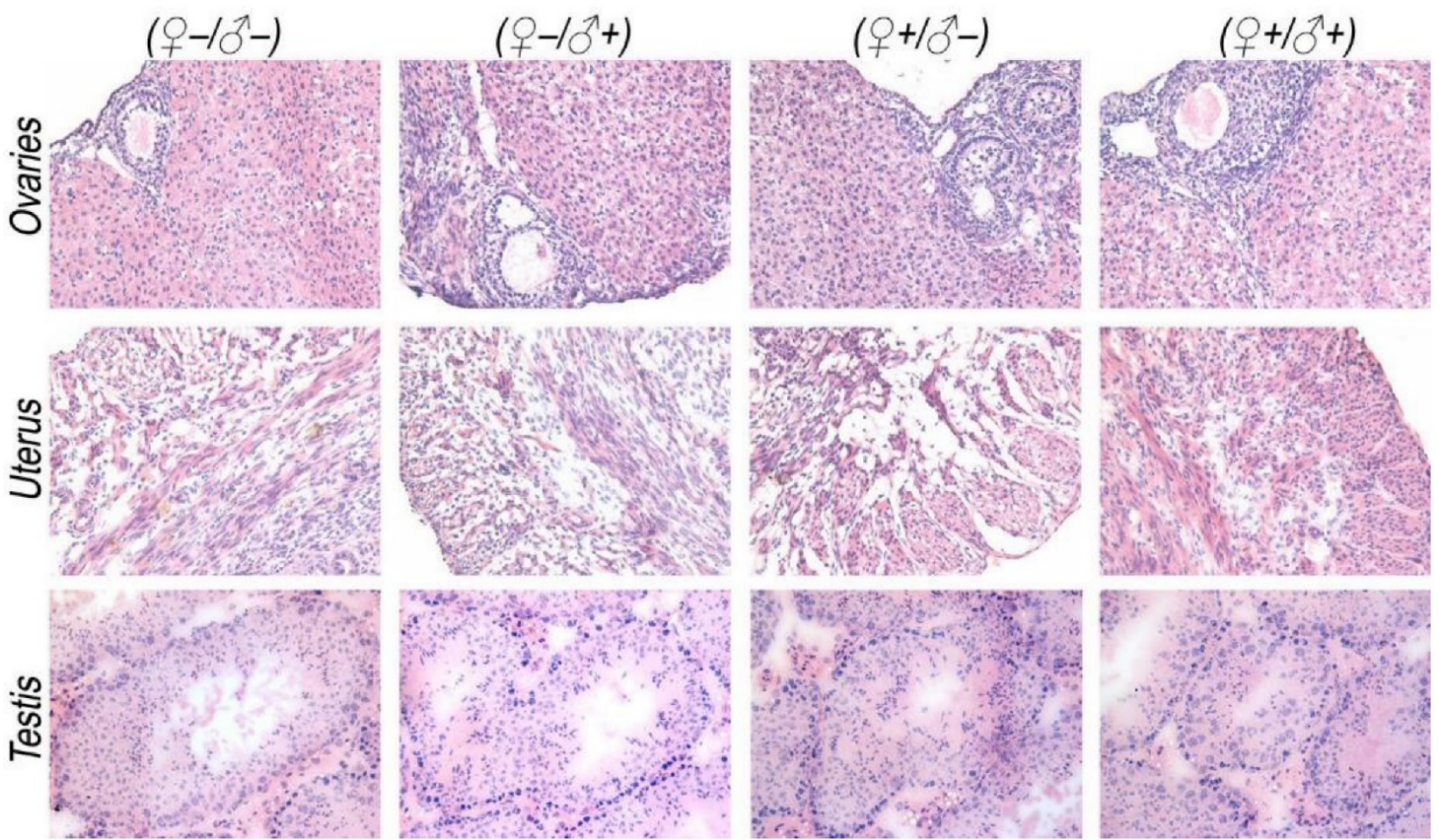

Figure 10. Histological images from the major reproductive organs of the F1 mice, showing no observable differences throughout the four different experimental

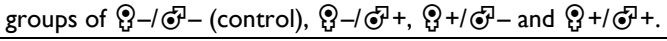

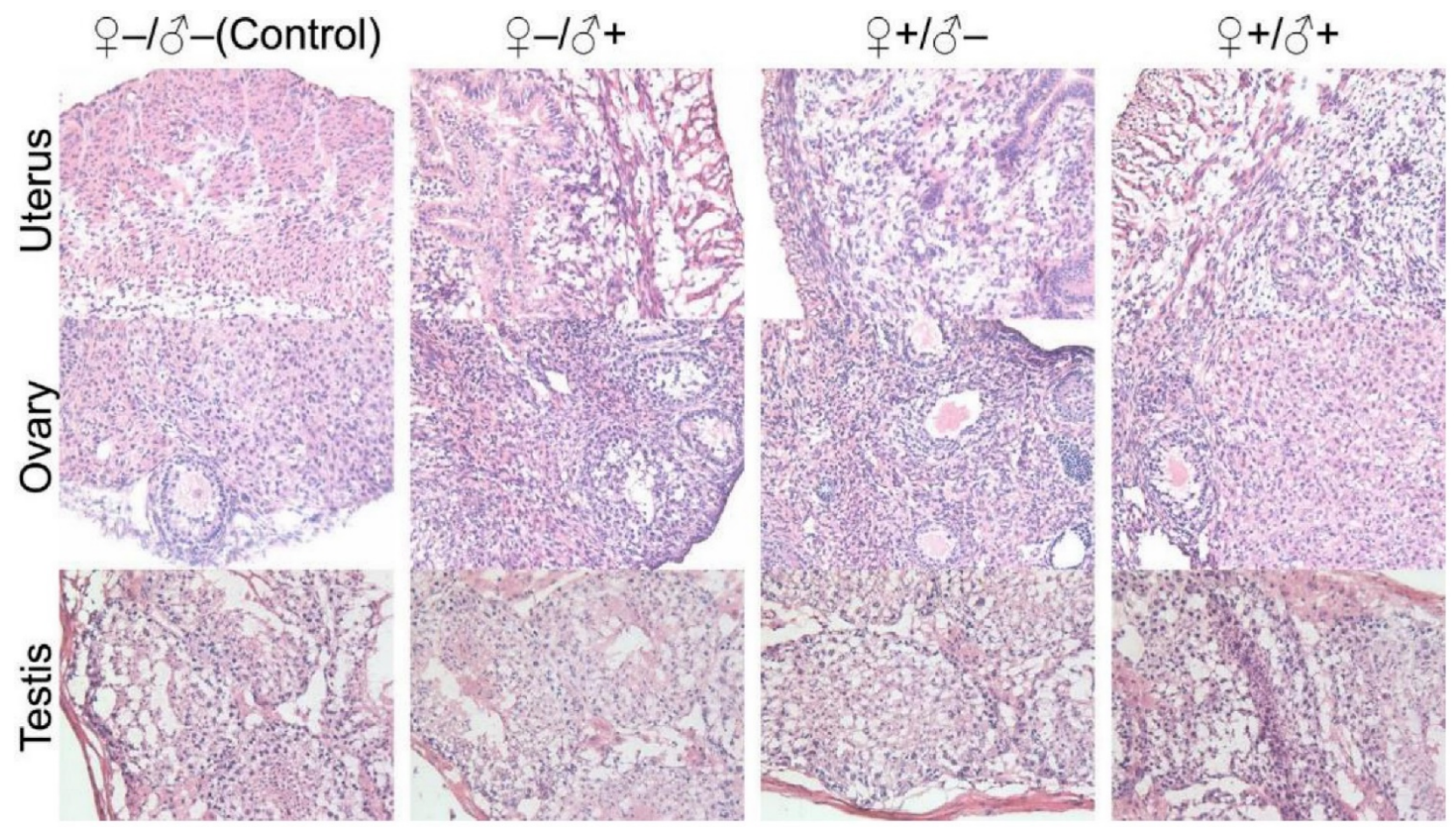

Figure 11. Histological images from the major reproductive organs of the F2 mice, including the female uterus and ovary and the male testis, showing no observable differences throughout the four different experimental groups of $\&-/ \odot-$ (control), $\&-/ \odot+, \&+/ \odot-$ and $\&+/ \odot+$.

Various factors such as reactive oxygen species generation and size effects have been reported to cause QD toxicity in vivo,[29, 30] but the pressing questions from the QD research community are: i) what will happen if the QDs are degraded in the body? ii) will they cause dysfunction of the major 
organs? iii) will the degradation of QDs negatively impact the reproductive organs? and iv) if the reproductive organs are damaged by the QDs at the cellular level, will it cause have an adverse impact on subsequent generations? Cadmium toxicity to the reproductive system has been well documented. An acute cadmium salt dosage of $20 \mu \mathrm{mol} / \mathrm{kg}$ body weight in pregnant Wistar rats was reported to cause severe placental damage and a mortality rate of over $70 \% .[31,32]$ In another report, pregnant mice $(\mathrm{QS} / \mathrm{CH})$ were exposed to cadmium through drinking water. The accumulative cadmium exposure induced fetal growth retardation and anemia, which was proposed to be due to the interference with placental transport of iron by cadmium.[33] The same report suggested that exposure to very low levels of cadmium may have little or no effect on the mother but may interfere with the growth and blood formation of the fetus. In the present study, we did not observe placental damage or fetus growth retardation in any of the experimental groups. This indicates that the QDs introduced two weeks before conception were successfully protected by the core/shell structure and the phospholipid encapsulation. They did not undergo rapid degradation to release sufficient cadmium ions to induce placental damage during the term of pregnancy. It should be noted that although acute toxicity could be avoided by robust particle coatings of cadmium based QDs, a two-year long study by Fitzpatrick et al. showed that the QDs will eventually break down, which increases the risk of chronic cadmium toxicity from the QDs[34]. Another possible source of pregnancy complications is the transplacental transport of nanoparticles. Several types of nanoparticles, including silica, titanium oxide, carbon black, quantum dots, silver nanoparticles and magnetic nanoparticles have been reported to cross the placental barrier in both in vitro and in vivo models.[12, 15, 35-40] Because of their wide application as additives in cosmetics, the potential toxicity risk of titanium oxide nanoparticles to pregnancy has been carefully investigated. Takeda et al. found that subcutaneously administered titanium oxide nanoparticles transferred from pregnant mice to their offspring and affected the genital and cranial nerve systems in the male offspring.[36] Yamashita et al. have shown that silica and titanium oxide nanoparticles with sizes of $70 \mathrm{~nm}$ and $35 \mathrm{~nm}$, respectively, can cause pregnancy complications in mice through the activation of coagulation, complement and oxidative stress in the placenta. Further investigation also indicated that the surface chemistry of the nanoparticles played an important role; modification of the surface with carboxyl or amine groups abrogated the negative effects.[15] More recently, Trouiller et al. have shown that in utero exposure to titanium oxide nanoparticles resulted in an increased frequency of DNA deletions in the fetus and caused genotoxicity through a secondary genotoxic mechanism associated with inflammation and/or oxidative stress.[41] In addition to titanium oxide nanoparticles, other materials were also reported to induce abnormalities to the offspring through prenatal exposure. Umezawa et al. found that maternal exposure to carbon black nanoparticles on the fifth and the ninth days of pregnancy in ICR mice induced renal abnormalities in the kidneys of offspring which was similar to tubulointerstitial fibrosis in diabetic nephropathy.[42] Prenatal exposure to carbon black nanoparticles through intratracheal instillation was also reported to affect the sperm production in the F2 generation.[43] In a study by Jo et al., rats treated with zinc oxide nanoparticles showed reduced number of born/live pups, decreased body weight of pups and increased fetal resorption.[44] All these studies have indicated that prenatal exposure to nanoparticles may cause complications to the pregnancy and the offspring. However, in the present study, the exposure to QDs two weeks before conception did not induce any significant abnormalities during pregnancy or in two generations of offspring from common parents, despite the fact that the QDs remained present in the organs of the treated animals. A major difference between the present study and the above mentioned studies is that our study provided a two-week "buffering period" between the QD administration and conception. The results show that this buffering period has greatly reduced the potential toxicity risk of the QDs to pregnancy and the offspring. Yang et al. have shown that the plasma cadmium concentration dropped to background levels in about a week after QD injection through the tail vein $(40 \mathrm{pmol})$ and could not be detected after two weeks.[45] In our study, the two-week buffering period has allowed the QDs to be cleared from the blood circulation and sequestered, mainly in the liver and spleen. As a result, the amount of QDs in circulation is minimal during pregnancy and thus the QDs were not passed to the fetuses through transplacental transmission during the fetal development. On the other hand, the degradation of QDs is a very slow process that involves complicated metabolic steps to break down the particles. This degradation is a long term process can take years and may not be complete within the mouse life span.[46, 47] Consequently, the release of cadmium ions is extremely low, and did not cause significant toxicity to the treated mice or their offspring. Nonetheless, the QDs administered were mostly captured by the liver, 
spleen and lymph nodes within the first few days, in agreement with previous studies.[9, 48, 49] More importantly, we should emphasize that due to the lack of an active biochemical process for cadmium elimination coupled with renal reabsorption, only $0.001 \%$ of cadmium in the body is excreted per day.[50] As the degradation of QDs happens eventually, the re-distribution and accumulation of cadmium among different organs may start to play an important role in the chronic toxicity to the animals.[51, 52] Because the major target of cadmium toxicity is the kidney, chronic renal failure could start as the accumulative cadmium concentration in the kidneys reaches the threshold. At that point, unhealthy individuals would be unlikely to experience successful pregnancy with normal reproduction outcome[53]. As nanomaterials have found increasingly wide applications in research, industry, and daily life, their potential risk to public health must be extensively evaluated and special attention should be focused on reproductive health. Although warnings have been sent to the community that nanoparticle exposure would induce a high risk for pregnancy complications and health risks to the offspring, our study suggests that a buffering time period between the exposure and conception could greatly reduce that risk. We believe this information can be of great value, particularly to those who have experienced unintentional exposure to nanoparticles.

\section{Conclusion}

In conclusion, we have evaluated the effects of QDs on reproductive health in Kunming mice. CdSe/CdS/ZnS QDs were encapsulated with PEGylated phospholipid micelles and intravenously administered to female mice, male mice, or both (the F0 generation) at a dosage of $0.81 \mathrm{mg} \mathrm{Cd} / \mathrm{kg}$ body weight. Rather than direct exposure during pregnancy, a buffering period of two weeks was introduced between the QD injection and conception. The pregnancy outcomes and the health status of the offspring were carefully monitored and evaluated. Our results showed that with such a buffering period, the QDs were retained by the F0 mice and mainly accumulated in the major organs including the liver, spleen, lymph nodes and bone marrow. However, through blood tests and histological evaluations, we showed that the QD exposure did not cause adverse effects to the treated mice. The pregnancy was not disturbed by the QD exposure and no complications were observed. The pregnancy outcomes were normal in each of the experimental groups. More importantly, through behavior monitoring, blood tests and histological evaluations, two generations of the offspring were observed to be in normal and healthy condition. There were no significant differences between the offspring of the four experimental and control groups. Our results suggest that QD exposure with a short buffering period before conception does not cause overt pregnancy complications or significant toxicity effects to subsequent generations. This study suggests that establishing a safety period between potential exposure to nanomaterials and conception can reduce risks to reproductive health.

\section{Acknowledgements}

This study was supported by the National Natural Science Foundation of China (No. 51371197, 61107017), the Start-up grant (M4080141.040) from Nanyang Technological University, Tier 1 Academic Research Funds (M4010360.040 RG29/10) and Tier 2 Research Grant MOE2010-T2-2-010 (4020020.040 ARC2/11) from Singapore Ministry of Education.

\section{Competing Interests}

The authors have declared that no competing interest exists.

\section{References}

[1] Chan WC, Nie S. Quantum dot bioconjugates for ultrasensitive nonisotopic detection. Science. 1998;281:2016-8.

[2] Bruchez M, Moronne M, Gin P, Weiss S, Alivisatos AP. Semiconductor nanocrystals as fluorescent biological labels. Science. 1998;281:2013-6.

[3] Michalet X, Pinaud FF, Bentolila LA, Tsay JM, Doose S, Li JJ, et al. Quantum dots for live cells, in vivo imaging, and diagnostics. science. 2005;307:538-44.

[4] Wang Y, Hu R, Lin G, Roy I, Yong K-T. Functionalized Quantum Dots for Biosensing and Bioimaging and Concerns on Toxicity. ACS applied materials \& interfaces. 2013;5:2786-99.

[5] Zrazhevskiy P, Sena M, Gao X. Designing multifunctional quantum dots for bioimaging, detection, and drug delivery. Chemical Society Reviews. 2010;39:4326-54.

[6] Li J, Zhu J-J. Quantum dots for fluorescent biosensing and bio-imaging applications. Analyst. 2013;138:2506-15.

[7] Derfus AM, Chan WC, Bhatia SN. Probing the cytotoxicity of semiconductor quantum dots. Nano letters. 2004;4:11-8.

[8] Ipe BI, Lehnig M, Niemeyer CM. On the generation of free radical species from quantum dots. Small. 2005;1:706-9.

[9] Hauck TS, Anderson RE, Fischer HC, Newbigging S, Chan WCW. In vivo Quantum-Dot Toxicity Assessment. Small. 2010;6:138-44.

[10] Gao X, Cui Y, Levenson RM, Chung LWK, Nie S. In vivo cancer targeting and imaging with semiconductor quantum dots. Nat Biotech. 2004;22:969-76.

[11] Yong K-T, Law W-C, Hu R, Ye L, Liu L, Swihart MT, et al. Nanotoxicity assessment of quantum dots: from cellular to primate studies. Chemical Society Reviews. 2013;42:1236-50.

[12] Chu M, Wu Q, Yang H, Yuan R, Hou S, Yang Y, et al. Transfer of Quantum Dots from Pregnant Mice to Pups Across the Placental Barrier. Small. 2010;6:670-8

[13] Yang H, Sun C, Fan Z, Tian X, Yan L, Du L, et al. Effects of gestational age and surface modification on materno-fetal transfer of nanoparticles in murine pregnancy. Sci Rep. 2012;2.

[14] Wick P, Malek A, Manser P, Meili D, Maeder-Althaus X, Diener L, et al. Barrier capacity of human placenta for nanosized materials. Environmental health perspectives. 2010;118:432-6.

[15] Yamashita K, Yoshioka Y, Higashisaka K, Mimura K, Morishita Y, Nozaki M, et al. Silica and titanium dioxide nanoparticles cause pregnancy complications in mice. Nat Nano. 2011;6:321-8.

[16] Yoshida S, Hiyoshi K, Ichinose T, Takano H, Oshio S, Sugawara I, et al. Effect of nanoparticles on the male reproductive system of mice. International Journal of Andrology. 2009;32:337-42.

[17] Yoshida S, Hiyoshi K, Oshio S, Takano H, Takeda K, Ichinose T. Effects of fetal exposure to carbon nanoparticles on reproductive function in male offspring. Fertility and Sterility. 2010;93:1695-9.

[18] Bai Y, Zhang Y, Zhang J, Mu Q, Zhang W, Butch ER, et al. Repeated administrations of carbon nanotubes in male mice cause reversible testis damage without affecting fertility. Nat Nano. 2010;5:683-9. 
[19] Yang B, Yang L, Hu R, Sheng Z, Dai D, Liu Q, et al. Fabrication and characterization of small optical ridge waveguides based on SU-8 polymer. Lightwave Technology, Journal of. 2009;27:4091-6.

[20] Ema M, Kobayashi N, Naya M, Hanai S, Nakanishi J. Reproductive and developmental toxicity studies of manufactured nanomaterials. Reproductive Toxicology. 2010;30:343-52.

[21] Manna L, Scher EC, Li L-S, Alivisatos AP. Epitaxial Growth and Photochemical Annealing of Graded CdS/ZnS Shells on Colloidal CdSe Nanorods. Journal of the American Chemical Society. 2002;124:7136-45.

[22] Ye L, Yong K-T, Liu L, Roy I, Hu R, Zhu J, et al. A pilot study in non-human primates shows no adverse response to intravenous injection of quantum dots. Nat Nano. 2012;7:453-8.

[23] Lin G, Ouyang Q, Hu R, Ding Z, Tian J, Yin F, et al. In vivo toxicity assessment of non-cadmium quantum dots in BALB/c mice. Nanomedicine: Nanotechnology, Biology and Medicine. 2015;11:341-50.

[24] Vähäkangas K, Myllynen P. Drug transporters in the human blood-placental barrier. British Journal of Pharmacology. 2009;158:665-78.

[25] Bhabra G, Sood A, Fisher B, Cartwright L, Saunders M, Evans WH, et al. Nanoparticles can cause DNA damage across a cellular barrier. Nature nanotechnology. 2009;4:876-83.

[26] Ballou B, Lagerholm BC, Ernst LA, Bruchez MP, Waggoner AS. Noninvasive imaging of quantum dots in mice. Bioconjugate chemistry. 2004;15:79-86.

[27] Liu J, Law W-C, Liu J, Hu R, Liu L, Zhu J, et al. Toxicity assessment of phospholipid micelle-encapsulated cadmium-based quantum dots using Kunming mice. RSC Advances. 2013;3:1768-73.

[28] Hong Y, Lam JWY, Tang BZ. Aggregation-induced emission. Chemical Society Reviews. 2011;40:5361-88.

[29] Aillon KL, Xie Y, El-Gendy N, Berkland CJ, Forrest ML. Effects of nanomaterial physicochemical properties on in vivo toxicity. Advanced Drug Delivery Reviews. 2009;61:457-66.

[30] Hardman R. A toxicologic review of quantum dots: toxicity depends on physicochemical and environmental factors. Environmental health perspectives. 2006;114:165-72.

[31] Pařizek J. Vascular changes at sites of oestrogen biosynthesis produced by parenteral injection of cadmium salts: the destruction of placenta by cadmium salts. Journal of Reproduction and Fertility. 1964;7:263-5.

[32] Pařízek J. The peculiar toxicity of cadmium during pregnancy-an experimental 'toxaemia of pregnancy' induced by cadmium salts. Journal of Reproduction and Fertility. 1965;9:111-2

[33] Webster WS. Cadmium-Induced Fetal Growth Retardation in the Mouse. Archives of Environmental Health: An International Journal. 1978;33:36-42

[34] Fitzpatrick JAJ, Andreko SK, Ernst LA, Waggoner AS, Ballou B, Bruchez MP. Long-term Persistence and Spectral Blue Shifting of Quantum Dots in Vivo. Nano Letters. 2009;9:2736-41.

[35] Poulsen MS, Mose T, Maroun LL, Mathiesen L, Knudsen LE, Rytting E. Kinetics of silica nanoparticles in the human placenta. Nanotoxicology. 2015 May;9 (Suppl 1):79-86.

[36] Takeda K, Suzuki K-i, Ishihara A, Kubo-Irie M, Fujimoto R, Tabata M, et al. Nanoparticles transferred from pregnant mice to their offspring can damage the genital and cranial nerve systems. Journal of Health Science. 2009;55:95-102.

[37] Jackson P, Hougaard KS, Boisen AMZ, Jacobsen NR, Jensen KA, Møller P, et al. Pulmonary exposure to carbon black by inhalation or instillation in pregnant mice: Effects on liver DNA strand breaks in dams and offspring. Nanotoxicology. 2012;6:486-500.

[38] Noori A, Parivar K, Modaresi M, Messripour M, Yousefi MH, Amiri GR. Effect of magnetic iron oxide nanoparticles on pregnancy and testicular development of mice. African Journal of Biotechnology. 2013;10:1221-7.

[39] Jackson P, Halappanavar S, Hougaard KS, Williams A, Madsen AM, Lamson JS, et al. Maternal inhalation of surface-coated nanosized titanium dioxide (UV-Titan) in C57BL/6 mice: effects in prenatally exposed offspring on hepatic DNA damage and gene expression. Nanotoxicology. 2013;7:85-96.

[40] Lee Y, Choi J, Kim P, Choi K, Kim S, Shon W, et al. A Transfer of Silver Nanoparticles from Pregnant Rat to Offspring. Toxicological research. 2012;28:139.

[41] Trouiller B, Reliene R, Westbrook A, Solaimani P, Schiestl RH. Titanium dioxide nanoparticles induce DNA damage and genetic instability in vivo in mice. Cancer research. 2009;69:8784-9.

[42] Umezawa M, Kudo S, Yanagita S, Shinkai Y, Niki R, Oyabu T, et al. Maternal exposure to carbon black nanoparticle increases collagen type VIII expression in the kidney of offspring. The Journal of Toxicological Sciences. 2011;36:461-8.

[43] Kyjovska ZO, Boisen AMZ, Jackson P, Wallin H, Vogel U, Hougaard KS. Daily sperm production: Application in studies of prenatal exposure to nanoparticles in mice. Reproductive Toxicology. 2013;36:88-97.

[44] Jo E, Seo G, Kwon J-T, Lee M, Lee Bc, Eom I, et al. Exposure to zinc oxide nanoparticles affects reproductive development and biodistribution in offspring rats. The Journal of Toxicological Sciences. 2013;38:525-30.

[45] Yang RS, Chang LW, Wu J-P, Tsai M-H, Wang H-J, Kuo Y-C, et al. Persistent tissue kinetics and redistribution of nanoparticles, quantum dot 705, in mice: ICP-MS quantitative assessment. Environmental Health Perspectives. 2007;115:1339.

[46] Lovrić J, Cho SJ, Winnik FM, Maysinger D. Unmodified Cadmium Telluride Quantum Dots Induce Reactive Oxygen Species Formation Leading to Multiple Organelle Damage and Cell Death. Chemistry \& Biology. 2005;12:1227-34
[47] Mancini MC, Kairdolf BA, Smith AM, Nie S. Oxidative Quenching and Degradation of Polymer-Encapsulated Quantum Dots: New Insights into the Long-Term Fate and Toxicity of Nanocrystals in Vivo. Journal of the American Chemical Society. 2008;130:10836-7.

[48] Fischer HC, Liu L, Pang KS, Chan WCW. Pharmacokinetics of Nanoscale Quantum Dots: In Vivo Distribution, Sequestration, and Clearance in the Rat. Advanced Functional Materials. 2006:16:1299-305.

[49] Gopee NV, Roberts DW, Webb P, Cozart CR, Siitonen PH, Warbritton AR, et al. Migration of Intradermally Injected Quantum Dots to Sentinel Organs in Mice. Toxicological Sciences. 2007;98:249-57.

[50] Satarug S, Moore MR. Adverse health effects of chronic exposure to low-level cadmium in foodstuffs and cigarette smoke. Environmental health perspectives. 2004;112:1099-103.

[51] Barbier O, Jacquillet G, Tauc M, Cougnon M, Poujeol P. Effect of Heavy Metals on, and Handling by, the Kidney. Nephron Physiology. 2005;99:p105-p10.

[52] Bernard A. Renal dysfunction induced by cadmium: biomarkers of critical effects. Biometals. 2004;17:519-23.

[53] Imbasciati E, Pardi G, Capetta P, Ambroso G, Bozzetti P, Pagliari B, et al. Pregnancy in Women with Chronic Renal Failure. American Journal of Nephrology. 1986;6:193-8. 